color then becomes faintly yellow and remains so until decomposition sets in above $300^{\circ}$. The anhydrous pyrimidine dissolved in alkali giving a deep green solution, which became red when the solution was acidified with acetic acid. The addition of hydrochloric acid discharges the color and produces a precipitate of the pyrimidine.

Calculated for $\mathrm{C}_{6} \mathrm{H}_{6} \mathrm{O}_{3} \mathrm{~N}_{4} \mathrm{~S} .1 / 2 \mathrm{H}_{2} \mathrm{O}: \mathrm{N}, 26.48 ; \mathrm{H}_{2} \mathrm{O}, 4.26$.

Found:

$\mathrm{N}, 26.34 ; \mathrm{H}_{2} \mathrm{O}, 4.9$

Diethyl Ureidomalonate, $\mathrm{NH}_{2} \mathrm{CONH} . \mathrm{CH}\left(\mathrm{COOC}_{2} \mathrm{H}_{5}\right)_{2}$.-This compound is formed at once when potassium cyanate reacts in a concentrated aqueous solution with the hydrochloride of diethyl aminoacetate. The reaction is complete in $3-4$ minutes and the yield of ester is $75 \%$ of the theoretical. The urea is difficultly soluble in hot alcohol, from which it crystallizes, on cooling, in octahedra. It melts at $173^{\circ}$.

Calculated for $\mathrm{C}_{8} \mathrm{H}_{14} \mathrm{O}_{6} \mathrm{~N}_{2}: \mathrm{N}, 12.83$; found: $\mathrm{N}, 12.70$.

An attempt to obtain pseudouric acid by condensation of this ester with urea, in the presence of sodium ethylate, was unsuccessful. This is apparently due to the fact that the sodium salt of diethyl ureidomalonate is extremely difficultly soluble in alcohol.

$$
\text { 2-Thio-6-oxy-4,5-diaminopyrimidine, }\left.\left.\right|_{\mathrm{NH}} ^{\mathrm{CS}}\right|_{\mathrm{CNH}_{2}} ^{\mathrm{NH}-\mathrm{NH}}
$$

was obtained by digesting an alcoholic solution of aminomalonic nitrile with thiourea and the required proportion of sodium ethylate. The alcoholic solution was boiled for 5 hours on the steam bath, and the pyrimidine isolated in the usual manner. It was purified by decolorization of its alkaline solution with bone coal and then precipitating from the alkaline solution with acetic acid. It had no definite decomposition point and after drying to constant weight at $100^{\circ}$ a nitrogen determination (Kjeldahl) gave the following result: The yield was small.

NEW HAVEN, CoNs.

[CONTRIBUTIONS FROM THE SHEFField ChEMICAL LABORATORY OF YalE UNIVERSTTY.] RESEARCHES ON HYDANTOINS. XXVII. SYNTHESIS OF HYDANTOIN-4-CARBOXAMIDE.

By Treat B. Johnson AND BEN H. NICOLET. Received November 24, 1913.

The mechanism of the reaction, by which alloxans are formed by the oxidation of uric acids, has been correctly interpreted by Biltz. This investigator has shown, in his recent work on the oxidation of purines, that these transformations (oxidation reactions) involve two independent 
reactions, namely, a formation of uric acid glycols, by addition of hydroxyl groups at the double bond between the 4 and 5 positions of the purine ring, and finally a dissociation of the glycol into alloxan and urea. ${ }^{1}$ The complete oxidation of uric acid, I, to alloxan, III, and urea may therefore, be expressed by the following equation:

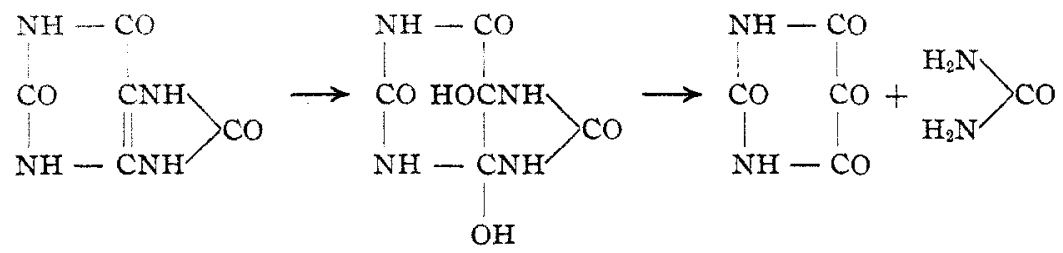

I.

II.

III.

Biltz has also confirmed the earlier observations of Fischer and finds that the stability of the glycols, II, is greatly increased by the introduction of alkyl radicals into the imide groups of the uric acids. Furthermore, he has also made the interesting observation that the same glycols can also be synthesized easily by addition of ureas to alloxans. For example, the dimethyluric acid glycol, V, is formed smoothly by condensation of alloxan with dimethylurea in aqueous and acetic acid solutions. In other words, the transformation of a uric acid glycol into an alloxan and urea is a reversible reaction. Biltz designates this characteristic change as an "Alloxan-Abban" of uric acids.

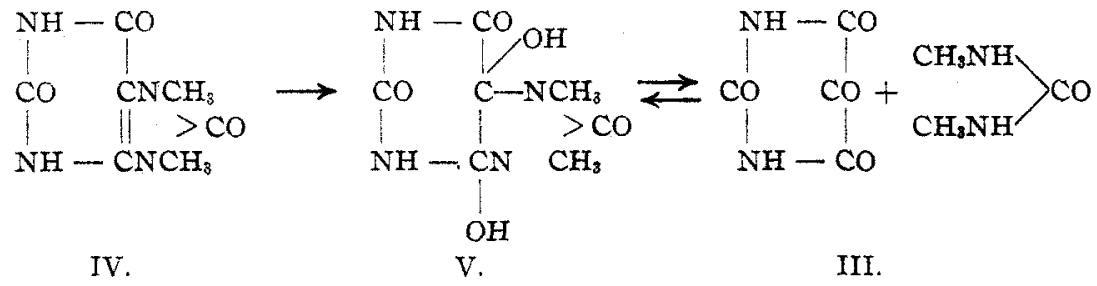

These glycols can also dissociate in an entirely different manner than that represented above. They can undergo what Biltz calls a "CaffolidAbban." $\mathrm{He}$ contributes the interesting observation that the pyrimidine ring is also easily ruptured, under certain conditions, with formation of characteristic hydantoin derivatives. For example, the glycol from tetramethyluric acid, VII, when allowed to stand in aqueous or acetic acid solutions, in transformed smoothly into the 5-hydroxyhydantoylurea, VIII. This compound is, however, unstable in the presence of alkali and undergoes hydrolysis easily, giving a salt of a hydroxyacid, which condenses to the caffolid derivative, IX, when warmed with hydrochloric acid. This characteristic derivative on more intense hydrolysis is transformed into the corresponding acid amide, $\mathrm{X}$, which finally can be con-

${ }^{1}$ Biltz, Ber., 43, 1589, I600; Biltz and Krebs, Ibid., 43, I5 II, 1618; 44, 282 ; Biltz and Topp, Ibid., 44, 1511, 1524; Topp, Inaug. Diss., Kiel (I911). 
verted by reduction with hydriodic acid into the hydantoin derivative, XI. These various changes involved in Biltz's "Caffolid-Abbau" of tetramethyluric acid, VI, may be represented as follows:

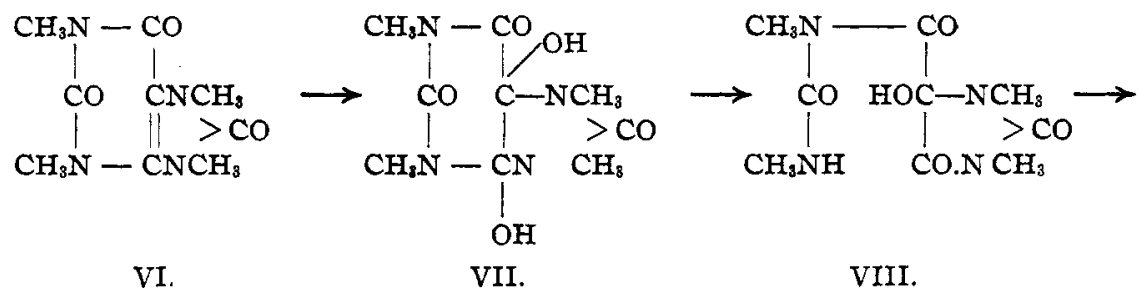

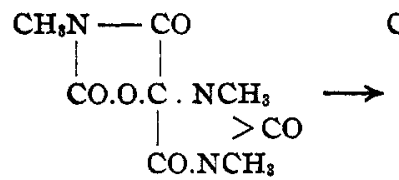

IX.<smiles>CCOC(=O)C(O)C(=O)NC</smiles>

X.<smiles>CCNC(=O)C(C(C)=O)C(C)=O</smiles>

$\mathrm{XI}$.

He also applied the same reactions successfully with $1,3,7$-trimethyluric acid, XII, and obtained methylhydantoylmethylamide, XIV. This hydantoin is identical with hydrocaffuric acid, which Fischer ${ }^{1}$ obtained by reduction of caffuric acid with hydriodic acid.<smiles>CN1C(=O)C2CCN(CC2)C1=O</smiles>

XII.

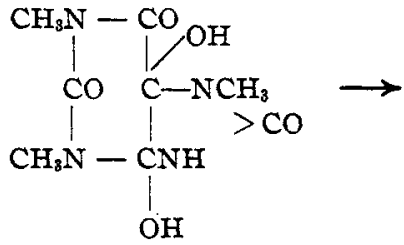

XIII.<smiles>CNC(=O)C(C)C(=O)NC(=O)O</smiles>

XIV.

Fischer has already shown that this hydantoin undergoes hydrolysis, by heating with barium hydroxide solution, forming methylamine and the barium salt of the corresponding hydantoincarboxylic acid, XV. On decomposing the barium salt with acids carbon dioxide was evolved and methylhydantoin, XVI, was obtained. Fischer ${ }^{2}$ writes as follows regarding the stability of this hydantoin acid: "Die freie Säure ist nur in kalter wässeriger Lösung beständig; beim Erwärmen zerfällt sie in Kohlensäure und Methylhydantoin."<smiles></smiles>

$\mathrm{XV}$.<smiles>CCC(=O)[O+]C(=O)NC(=O)CO</smiles>

$\mathrm{XVI}$.

1 Ann., 215, 282.

${ }^{2}$ Loc. cit. 
The two methylated hydantoins, XI and XIV, are representatives of a new type of hydantoins and are of especial interest on account of their possible relationship to oxonic acid, ${ }^{1} \mathrm{C}_{4} \mathrm{H}_{5} \mathrm{O}_{4} \mathrm{~N}_{3}$, an oxidation product of uric acid, whose constitution has not been definitely established. Piloty assigned to this compound the structure represented by formula XVII, but in the light of Biltz's work the isomeric structure XVIII, now appears more probable. These two hydantoins, XI and XIV, are derivatives of the hitherto unknown acid amide of hydantoin 4-carboxylic acid, XX, whose synthesis we now describe in this paper.
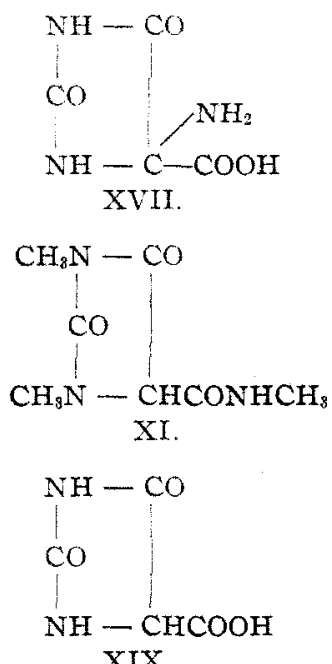

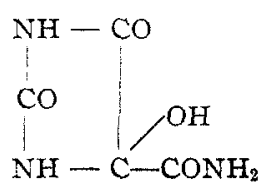

XVIII.
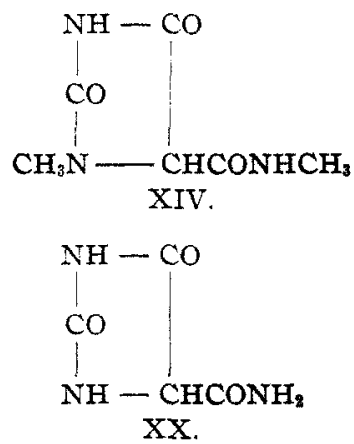

The starting point for our research was aminomalonamide, XXI. This acid amide, like the corresponding acid, has been made by a number of investigators. Conrad and Guthzeit ${ }^{2}$ obtained it, along with iminodimalonamide, XXII, by the action of alcoholic ammonia on diethyl

$$
\mathrm{NH}_{2} \mathrm{CH}\left(\mathrm{CONH}_{2}\right)_{2}
$$

XXI.

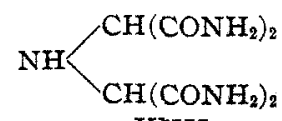

XXII.

chloromalonate. Whitely ${ }^{3}$ obtained it in the form of its hydriodide by the reduction of nitrosomalonamide with hydriodic acid. Piloty and Neresheimer ${ }^{4}$ prepared it by the action of ammonia on the hydrochloride of diethylaminomalonate.

The amide, which we used in our work, was prepared by the reduction of nitromalonamide with aluminum amalgam according to the directions

${ }^{1}$ Ann., 333, 91 .

2 Ber, $15,605$.

${ }^{3} \mathrm{~J}$. Chem. Soc., 77, 1040.

- Ber., 39, 5 I4. 
of Ruhemann and Orton. ${ }^{1}$ We also employed zinc and formic acid as the reducing agent but obtained formylmalonamide, which has previously been described by Conrad and Schulze. ${ }^{2}$ The same formyl compound is also formed by heating aminomalonamide with $85 \%$ formic acid. When warmed with barium hydroxide solution aminomalonamide is converted into barium aminomalonate.

We now find that Schotten and Baumann's reaction can be applied successfully with aminomalonamide and ethyl chloroformate, when the urethane represented by formula XXIII is formed in good yield. This interesting compound when treated with an equivalent amount of alkali, either in aqueous or alcoholic solution, undergoes a cyclic condensation, with loss of alcohol, forming hydantoin-4-carboxamide, or according to Biltz's nomenclature "hydantoylamide," XX. This compound is the prototype of the class of hydantoin compounds obtained by Biltz and the first of them to be obtained by direct synthesis. It was hoped that this compound might serve as a basis for the synthesis of caffuric acid and caffolid, but the yield of the amide was too small to make this feasible. Hydantoin-4-carboxamide, XX, is easily hydrolyzed, in the presence of alkali, and transformed into hydantoin.

We also investigated the behavior of this amide towards urea. Theoretically it might be expected that a substance of this constitution would condense, when heated with an excess of urea, forming uric acid, XXIV. Attempts, however, to effect such a change were unsuccessful. The negative result is of theoretical interest, however, because it shows that the hydantoin-4-carboxamide, $\mathrm{XX}$, is not an intermediate stage of the reaction when uric acid is formed by heating glycocoll with urea.
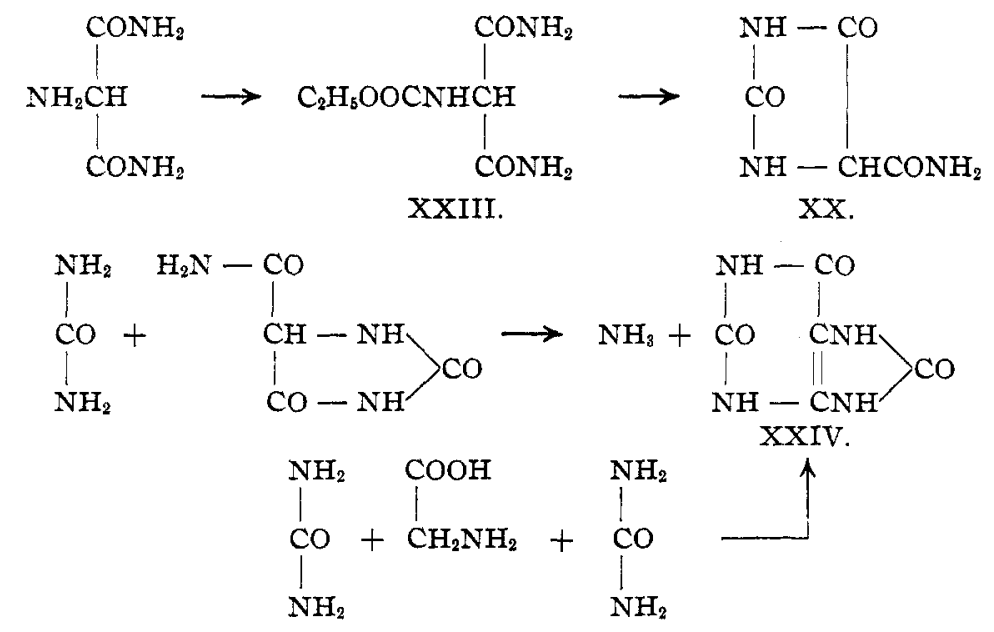

1 J. Chem. Soc., 67, 1002 .

${ }^{2}$ Ber., 42, 729, 735. 
Attempts to eliminate water from the formyl derivative of aminomalonamide, XXV, with formation of the glyoxaline compound 5-keto-4,5dihydroglyoxaline-4-carboxamide, XXVI, were likewise unsuccessful. The amide was heated to $150^{\circ}$ with an excess of formic acid, and the sodium salt was also heated for a long time at $180^{\circ}$, but in both cases ofter the treatment of the reaction products with hydrochloric acid, the only definite crystalline product identified was ammonium chloride.

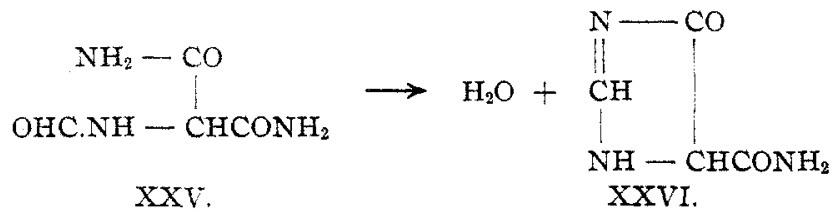

Aminomalonamide reacted smoothly with cyanic acid giving ureidomalonamide. On warming with barium hydroxide solution this was converted into the characteristic barium salt of ureidomalonic acid, which was obtained by Piloty and Finckh ${ }^{1}$ by hydrolysis of pseudouric acid with barium hydroxide. The amide also condensed normally with ethyl acetyldithiocarbamate, ${ }^{2}$ XXVII, and ethyl benzoylthioncarbamate, ${ }^{3}$ XXVIII, forming acetylthioureidomalonamide, XXIX, and benzoylpseudoethylureidomalonamide, XXX, respectively. The amide, XXIX, when digested with hydrochloric acid was converted smoothly into 2-thiohydantoin, XXXI.

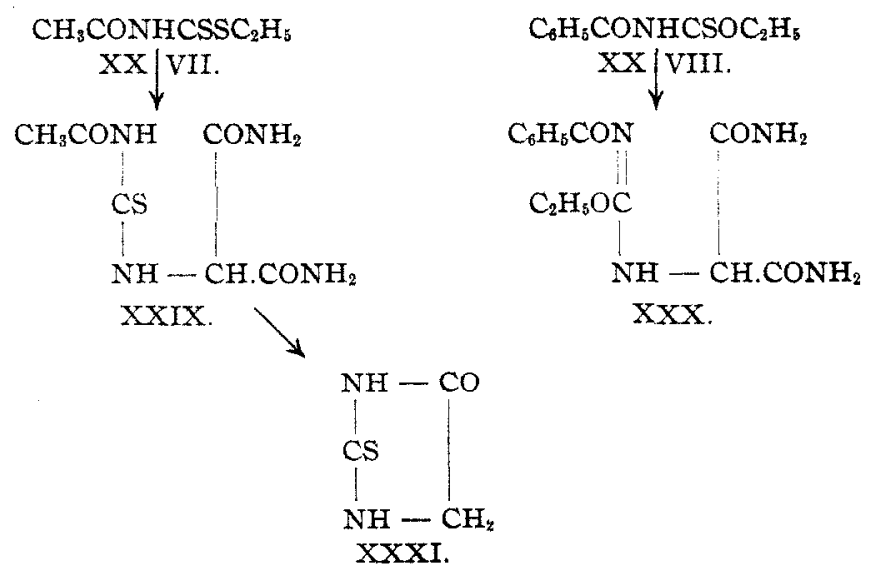

Experimental Part.

Nitromalonamide, $\mathrm{NO}_{2} \mathrm{CH}\left(\mathrm{CONH}_{2}\right)_{2}$. -This amide was prepared according to the method of Ruhemann and Orton. ${ }^{3}$ Their directions, however, are not very explicit, and consequently the following details are

1 Ann, 333, 7 .

${ }^{2}$ Wheeler, Nicolet and Johnson, Am. Chem. J., 46, 456 .

${ }^{3}$ Loc. cit. 
given. The malonamide was easily obtained in yields of $95 \%$ or more according to the directions of Freund. ${ }^{1}$ The amide, finely powdered, was added in small portions, with constant agitation, to seven times its weight of fuming nitric acid (sp. gr. I.5-r.55) kept cool in a freezing mixture. Not more than six grams of the amide should be used in any one preparation, and it was our experience that the addition of this amount to the nitric acid should not occupy more than five minutes. After all the malonamide had been added, the acid solution was quickly poured upon crushed ice, and the nitromalonamide separated quickly by filtration and washed with cold water. Long standing in the acid solution decreased the yield, which under the conditions described varied between 50 and $60 \%$. The pure amide melted with decomposition at temperatures which were easily varied between $168^{\circ}$ and $182^{\circ}$ according to the rate of heating. Ruhemann and Orton ${ }^{2}$ give $172^{\circ}$ as the melting point.

Aminomalonamide, $\mathrm{NH}_{2} \mathrm{CH}\left(\mathrm{CONH}_{2}\right)_{2}$.- Our procedure for the reduction of nitromalonamide was as follows: Twenty grams of aluminum turnings were amalgamated and washed free of alkali and mercuric chloride, and covered with $300 \mathrm{cc}$. of water. Twenty-five grams of nitromalonamide in $75 \mathrm{cc}$. of $10 \%$ aqueous ammonia were then added quickly and the mixture vigorously shaken and cooled to control the reaction, which at first is rather violent. After standing over night to complete the reaction, the solution was filtered, and the aluminium hydroxide triturated with $100 \mathrm{cc}$. of boiling water and again filtered. The combined filtrates were evaporated to dryness as quickly as possible, when the aminomalonamide, sufficiently pure for subsequent use, was obtained. The yield was I5 grams, corresponding to $75 \%$ of the calculated. Aminomalonamide easily undergoes hydrolysis, when warmed with barium hydroxide solution, giving the barium salt of aminomalonic acid. The salt is slightly soluble in cold water and crystallizes from hot water in prisms which do not loose weight when heated at $130^{\circ}$.

Calculated for $\mathrm{C}_{8} \mathrm{H}_{3} \mathrm{O}_{4} \mathrm{NBa}: \mathrm{N}, 5.5 \mathrm{I}$. Found: $\mathrm{N}, 5.47$.

Formylaminomalonamide, OCH.NH.CH $\left(\mathrm{CONH}_{2}\right)_{2}$.-This derivative, which was obtained by Conrad and Schulze ${ }^{2}$ by reduction of nitromalonamide with zinc dust and formic acid, is also easily prepared by heating aminomalonamide at $100^{\circ}$ with three times its weight of $85 \%$ formic acid. It crystallizes from dilute alcohol in slender, colorless prisms. When heated rapidly in a capillary tube it darkens at $195^{-200^{\circ}}$ and melts with effervescence at about $214^{\circ}$.

Calculated for $\mathrm{C}_{4} \mathrm{H}_{7} \mathrm{O}_{3} \mathrm{~N}_{3}: \mathrm{N}, 28.97$. Found: $\mathrm{N}, 28.56$.

Attempts to transform this formyl compound, by dehydration, into a glyoxaline compound were unsuccessful. In our first experiment, 3.0

1 Ber., I7, I33.

2 Loc. cit. 


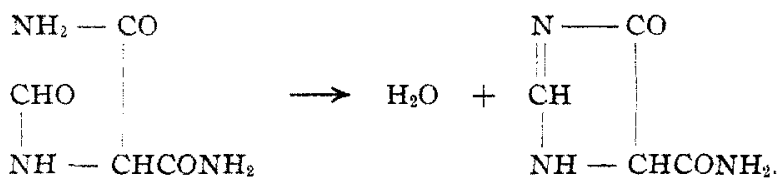

grams of aminomalonamide were heated to $150^{\circ}$ in a sealed tube, for two hours with six times its weight of $85 \%$ formic acid. There was considerable pressure when the tube was opened, and on evaporating the solution a viscous oil was obtained. The only crystalline product identified, however, was ammonium chloride, which was obtained by triturating the oil with hydrochloric acid. In a second experiment 2.0 grams of the formyl compound were transformed into its sodium salt, and this then heated for one hour in an oil bath at $180^{\circ}$. An examination of the residue did not reveal the presence of any glyoxaline compound. Treatment with hydrochloric acid yielded 1.0 gram of ammonium chloride. There was no evidence in either case that the desired reaction had taken place.

Carbethoxyaminomalonamide, $\mathrm{C}_{2} \mathrm{H}_{5} \mathrm{OOC}$. NH.CH$\left(\mathrm{CONH}_{2}\right)_{2}$, -This compound is easily obtained by application of Schotten and Baumann's reaction with aminomalonamide and ethylchloroformate. The methane is readily soluble in hot alcohol, moderately in cold, and crystallizes in characteristic rosettes of colorless leaflets, which melt at $178^{\circ}$. The compound is practically insoluble in water. The yield was $74 \%$ of the calculated value.

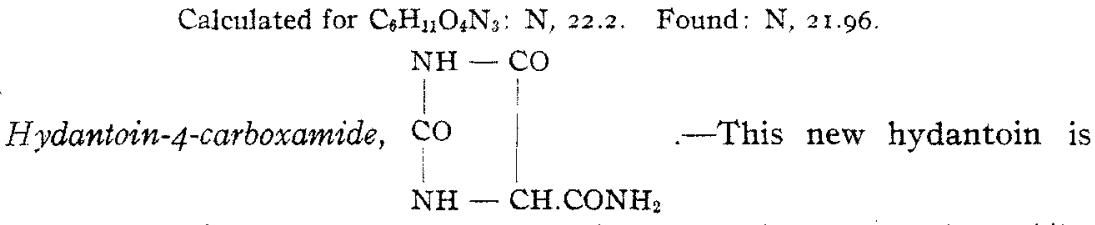

formed by the inner condensation of carbethoxyaminomalonamide. The amide was suspended in $20 \%$ alcohol containing exactly one molecular proportion of potassium hydroxide. On stirring at ordinary temperature it finally completely dissolved. After standing a few minutes the solution was then warmed to $40^{\circ}$ for a few seconds only, filtered from a slight residue, cooled, and then acidified with hydrochloric acid. The hydantoin separated, on cooling, in hexagonal prisms or thin plates, which melted with effervescence at $249^{\circ}$. The hydantoin is very soluble in water, difficultly soluble in alcohol. It was purified for analysis by crystallization from dilute alcohol. The yield of the hydantoincarboxamide was small. The amide group is very easily hydrolyzed in the presence of alkali, and a portion of the amide is transformed into hydantoin. Hydantoin was identified in the filtrates after removal of the carboxamide. The same acid amide is also formed, though in even smaller quantity, by the action of sodium ethylate on the urethane in absolute alcohol.

Calculated for $\mathrm{C}_{4} \mathrm{H}_{8} \mathrm{O}_{3} \mathrm{~N}_{3}: \mathrm{N}, 29.38$. Found: $\mathrm{N}, 29.4 \mathrm{I}$. 
One gram of this hydantoin-4-carboxamide and 3.0 grams of urea were ground together in a mortar, and the mixture heated for about $60-70$ minutes in an oil bath at $150^{\circ}$. Ammonia was evolved and the hydantoin was apparently completely decomposed by this treatment. No evidence was obtained of the formation of uric acid.<smiles>NC(=O)NC(=O)NC(=O)NC(=O)NNC(=O)NC(NC(=O)O)C(N)=O</smiles>

Ureidomalonamide, $\mathrm{NH}_{2} \mathrm{CONH} . \mathrm{CH}\left(\mathrm{CONH}_{2}\right)_{2}$. - Three grams of aminomalonamide were dissolved in a solution of $3 \mathrm{cc}$. of concentrated hydrochloric acid in $12 \mathrm{cc}$. of water. A saturated aqueous solution of 3.0 grams of potassium cyanate were then added. On allowing the solution to stand for several hours and finally diluting with an equal volume of alcohol, there separated 2.65 grams of ureidomalonamide, or $65 \%$ of the theoretical yield. This compound is difficultly soluble in alcohol and moderately soluble in cold water. It crystallizes from dilute alcohol in prismatic crystals (needles) which darken above $200^{\circ}$ and decompose at $200-225^{\circ}$ with effervescence according to the rate of heating. The amide was not easily freed from potassium chloride, and consequently the determinations of nitrogen were somewhat lower than the theoretical value. The difference in the molecular weights corresponding to the percentages of nitrogen calculated and found is, however, only 5, so that there can be no doubt as to the identity of the compound.

Calculated for $\mathrm{C}_{4} \mathrm{H}_{8} \mathrm{O}_{3} \mathrm{~N}_{4}: \mathrm{N}, 35.00$. Found: $\mathrm{N}, 34.00,34.03$.

Barium Salt of Ureidomalonic Acid, $\mathrm{NH}_{2} \mathrm{CONHCH}(\mathrm{COO})_{2} \mathrm{Ba} .2 \mathrm{H}_{2} \mathrm{O}$.This salt was formed when the above ureidomalonamide was heated with barium hydroxide. One gram of the amide was warmed for one hour at $100^{\circ}$ with 2.0 grams of barium hydroxide in $75 \mathrm{cc}$. of water. Ammonia was evolved and a colorless, crystalline precipitate of the barium salt was formed. This was separated by filtration, washed with hot water and dried for analysis at $100^{\circ}$. The salt is evidently identical with that prepared by Piloty and Finckh ${ }^{1}$ from ureidomalonic acid, which was obtained by the hydrolysis of pseudouric acid. The salt contained two molecules of water, which were determined by heating at $130^{\circ}$.

Calculated for $\mathrm{C}_{4} \mathrm{H}_{4} \mathrm{O}_{5} \mathrm{~N}_{2} \mathrm{Ba} .2 \mathrm{H}_{2} \mathrm{O}: \mathrm{H}_{2} \mathrm{O}$, 10.78. Found: $\mathrm{H}_{2} \mathrm{O}, 10.83$.

Calculated for $\mathrm{C}_{4} \mathrm{H}_{4} \mathrm{O}_{6} \mathrm{~N}_{2} \mathrm{Ba} .2 \mathrm{H}_{2} \mathrm{O}: \mathrm{N}, 8.4 \mathrm{O} ; \mathrm{Ba}, 4 \mathrm{r} .26$.

Found:

$\mathrm{N}, 8.35 ; \mathrm{Ba}, 4 \mathrm{r} .28$.

Acetylthioureidomalonamide, $\mathrm{CH}_{3} \mathrm{CONHCSNH.CH}\left(\mathrm{CONH}_{2}\right)_{2}$. - Two grams of aminomalonamide were added to a solution of 2.8 grams of ethyl acetyldithiocarbamate, $\mathrm{CH}_{3} \mathrm{CONH} . \mathrm{CSSC}_{2} \mathrm{H}_{5}$ in $30 \mathrm{cc}$. of alcohol,

1 Loc sit. 
and the mixture warmed gently on the steam bath for 24 hours. On: cooling, the thiourea separated. The yield was 2.3 grams. The compound. is difficultly soluble in both water and alcohol and crystallizes in fine, colorless, hair-like needles. They turned dark when heated above $220^{\circ}$, finally melting at about $254^{\circ}$ with strong effervescence.

$$
\text { Calculated for } \mathrm{C}_{6} \mathrm{H}_{10} \mathrm{O}_{3} \mathrm{~N}_{4} \mathrm{~S}: \mathrm{N}, 25.64 \text {. Found: } \mathrm{N}, 25.83,25.14 \text {. }
$$

Five-tenths of a gram of the above compound was digested for a few hours with an excess of $20 \%$ hydrochloric acid. The acid was then evaporated and the residue crystallized from water. Brown prisms separated. which melted at $228^{\circ}$ with decomposition. This contained sulfur and was: identified as 2-thiohydantoin. The hydrolysis of the thioureidomalonamide may therefore be expressed by the following equation:

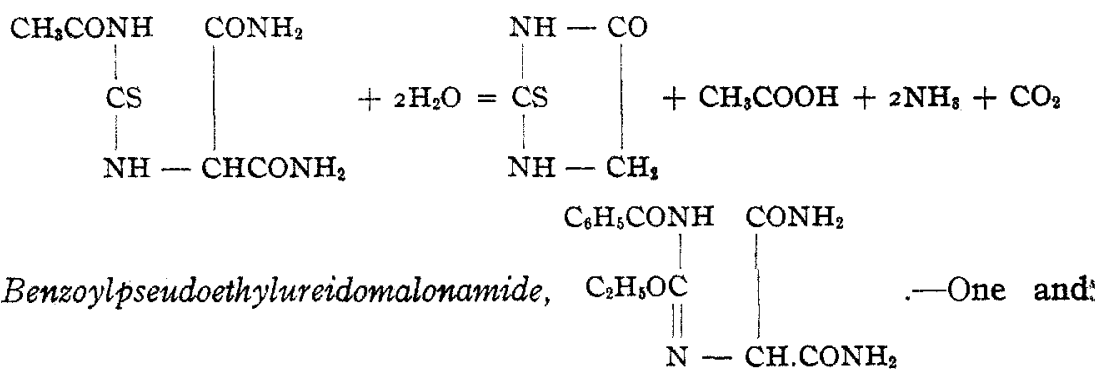

five-tenths grams of aminomalonamide were warmed for 15 minutes, at $100^{\circ}$, with an equivalent amount of ethyl benzoylthioncarbamate, $\mathrm{C}_{6} \mathrm{H}_{5} \mathrm{CONH} . \mathrm{CSOC}_{2} \mathrm{H}_{5}$ in $20 \mathrm{cc}$. of alcohol. Hydrogen sulfide was evolved, and the pseudourea separated. The compound is difficultly soluble in hot alcohol, from which it separates on cooling in colorless hair-like needles. The compound darkens when heated above $200^{\circ}$ and melts at $230^{-} 240^{\circ}$ with strong effervescence. The compound is very difficultly soluble in water. The yield was 3.0 grams, or $82 \%$ of the theoretical.

Calculated for $\mathrm{C}_{13} \mathrm{H}_{10} \mathrm{O}_{4} \mathrm{~N}_{4}: \mathrm{N}$, 19.15. Found: $\mathrm{N}, 19.4,19.3$.

New HaVEN, CONN.

[CONTRIBUTIONS FROM THE SHEFFIELD Chemical LABORATORY OF YALE UNIVERSITY.]

\section{RESEARCHES ON PYRIMIDINES. LXVII. THE CONDENSATION OF THIOUREA WITH ETHYL ALLYLACETOACETATE.}

by Treat B. Johnson and arthur J. Hill. Received December 20, 1913.

The behavior of thiourea, urea and guanidine towards diethyl allylmalonate (I), diethyl diallylmalonate (II), and diethyl allylbenzylmalonate (III), has been investigated by Johnson and Hill. ${ }^{1}$ With thiourea, no one of the three malonic esters condensed normally, in alcohol solution

1 Am. Chem. J., 45, 356; 46, 537 . 